\title{
EFFECTS OF EARLY CHANGES IN ORGAN DYSFUNCTIONS ONTHE OUTCOMES OF CRITICALLY ILL PATIENTS IN NEED OF RENAL REPLACEMENT THERAPY
}

\author{
Elizabeth Maccariello, Eduardo Rocha, Carla Valente, Lina Nogueira, Pedro \\ T. Rocha, Hélio Bonomo Jr, Luciana F. Serpa, Márcia Ismael, Ricardo V. R. \\ Valença, José E. S. Machado, Márcio Soares
}

doi: $10.1590 / \mathrm{S1807-59322008000300010}$

Maccariello E, Rocha E, Valente C, Nogueira L, Rocha PT, Bonomo Junior H et al. Effects of early changes in organ dysfunctions on the outcomes of critically ill patients in need of renal replacement therapy. Clinics. 2008;63:343-50.

INTRODUCTION: Acute kidney injury usually develops in critically ill patients in the context of multiple organ dysfunctions. OBJECTIVE: To evaluate the effect of changes in associated organ dysfunctions over the first three days of renal replacement therapy on the outcomes of patients with acute kidney injury.

METHODS: Over a 19-month period, we evaluated 260 patients admitted to the intensive care units of three tertiary-care hospitals who required renal replacement therapy for $>48 \mathrm{~h}$. Organ dysfunctions were evaluated by SOFA score (excluding renal points) on the first (D1) and third (D3) days of renal replacement therapy. Absolute (A-SOFA) and relative ( $\triangle$-SOFA) changes in SOFA scores were also calculated.

RESULTS: Hospital mortality rate was 75\%. Organ dysfunctions worsened (A-SOFA $>0$ ) in 53\%, remained unchanged (A-SOFA=0) in $17 \%$ and improved (A-SOFA $<0$ ) in $30 \%$ of patients; and mortality was lower in the last group ( $80 \%$ vs. $84 \%$ vs. $61 \%$, p $=0.003$ ). SOFA on D1 ( $\mathrm{p}<0.001)$, SOFA on D3 ( $\mathrm{p}<0.001)$, A-SOFA $(\mathrm{p}=0.019)$ and $\Delta$-SOFA $(\mathrm{p}=0.016)$ were higher in non-survivors. However, neither A-SOFA nor $\triangle$-SOFA discriminated survivors from non-survivors on an individual basis. Adjusting for other covariates (including SOFA on D1), A-SOFA and $\Delta$-SOFA were associated with increased mortality, and patients in whom SOFA scores worsened or remained unchanged had poorer outcomes.

CONCLUSIONS: In addition to baseline values, early changes in SOFA score after the start of renal replacement therapy were associated with hospital mortality. However, no prognostic score should be used as the only parameter to predict individual outcomes.

KEYWORDS: Sequential Organ Failure Score. Dialysis. Acute kidney injury. Mortality. Outcome.

\section{INTRODUCTION}

Acute kidney injury (AKI) occurs frequently in critically ill patients, and despite advances in intensive care and renal replacement therapies (RRT) in recent years, mortality rates remain exceedingly high. ${ }^{1-5}$ Many predictive factors

This work was performed at the intensive care units of Rede D'Or de Hospitais - Rio de Janeiro, Brazil. emaccariello@yahoo.com.br

Received for publication on January 28, 2008

Accepted for publication on March 17, 2008 for increased mortality have been identified in recent years, including older age, the need for RRT itself, the severity of comorbidities and associated organ failures..$^{1-4,6}$

AKI usually develops in critically ill patients in the context of multiple organ dysfunctions. ${ }^{3}$ Organ dysfunction scores are routinely used to evaluate these states in critically ill patients. Although no single characteristic or prognostic score should be used as only parameter to predict outcome on individual basis, the sequential evaluation of changes in organ dysfunctions during the first days of admission has been shown to refine outcome prediction in patients admitted to the intensive care unit (ICU) ${ }^{7-9}$ However, studies focusing on this 
topic in patients with AKI requiring RRT are both scant and limited by a retrospective design and relatively small sample size. ${ }^{10,11}$ The aim of the present study was to evaluate the effect of changes in associated organ dysfunctions over the first three days of RRT on the outcomes of a large cohort of patients admitted to the ICU with AKI.

\section{METHODS}

From December 2004 to May 2006, a prospective cohort study was performed at the medical-surgical ICU of three tertiary-care hospitals. Since this study did not interfere with clinical decisions related to patients' care, the Institutional Review Board approved it and waived the need for informed consent in all centers.

\section{Study Participants, Data Collection and Definitions}

During the study period, every patient with AKI or acute on chronic kidney injury in need of RRT was evaluated. AKI was classified according to the RIFLE criteria ${ }^{12}$ at the time of initiation of RRT. Patients with end-stage renal disease requiring chronic dialysis, those with non-renal indications for RRT and those who received RRT in the ICU for $\leq 48 \mathrm{~h}$ or had an ICU stay $\leq 48 \mathrm{~h}$ were not considered. For patients with readmissions, only the first admission was considered. Decisions to start, change the method, and cease RRT were made by the nephrologist and the intensivist responsible for the patient on an individual basis. Prescribed RRT modes were daily conventional dialysis, daily extended dialysis and continuous RRT (CRRT), taking into consideration the patient's hemodynamic status. ${ }^{4}$ CRRT was employed for patients receiving vasoactive drugs and for those with potential for hemodynamic instability. Oliguria was defined as urine output $<400 \mathrm{ml} /$ day.

Associated acute organ dysfunctions were evaluated by calculating the Sequential Organ Failure Assessment (SOFA) score, ${ }^{13}$ excluding renal points. For sedated patients, the Glasgow Coma Scale (GCS) prior to sedation was used. ${ }^{14}$ SOFA scores were determined on the first (D1) and on the third (D3) days of RRT. The absolute (A-SOFA) and relative $(\Delta$-SOFA) changes in SOFA scores over the first three days of RRT were determined as follows: A-SOFA $=$ SOFA on D3 - SOFA on D1; and $\triangle$-SOFA $=($ SOFA on D3 - SOFA on D1) / SOFA on D1. Patients with missing data for the calculation of SOFA scores on D1 or D3 were also excluded from the analysis. Patients were classified according to the A-SOFA into three categories: "improved" $(\mathrm{A}-\mathrm{SOFA}<0)$, "remained unchanged" $(\mathrm{A}-\mathrm{SOFA}=0)$ and "worsened" (A-SOFA $>0$ ). In addition, the following data were collected: age, gender, the Simplified Acute Physiology
Score (SAPS) $\mathrm{II}^{15}$ at ICU admission, previous health status, ${ }^{16}$ comorbidities, ${ }^{17}$ main reasons for ICU admission, premorbid renal function, need of mechanical ventilation and vasopressors for more than $24 \mathrm{~h}$ and contributing factors for AKI. The Charlson Comorbidity Index was used in the measurement of comorbidities. ${ }^{17}$ Sepsis was diagnosed using the criteria developed at the American College of Chest Physicians/Society of Critical Care Medicine consensus conference, ${ }^{18}$ and infection was diagnosed using criteria from the Centers for Diseases Control. ${ }^{19}$ Hospital mortality was the end-point of interest. End-of-life decisions (to withhold or withdraw life-support treatments) were made in regard to patients who did not recover from the acute illness despite full-code management.

\section{Data Presentation and Statistical Analysis}

Standard descriptive statistics were used to describe the study population. Continuous variables are presented as mean \pm standard deviation or median (25\%-75\% interquartile range). Univariate and multivariate logistic regression analyses were used to identify factors associated with hospital mortality. Linearity between continuous variables and the dependent variable was evaluated using locally weighted scatterplot smoothing (LOWESS)..$^{20}$ Variables yielding $P$ values $<0.2$ by univariate analysis and variables considered clinically important were entered in a forward multivariate logistic regression analysis. Results of both uni- and multivariate analyses were summarized by estimating odds ratios (OR) and respective $95 \%$ confidence intervals (CI). Possible interactions and colinearity were tested. The area under the receiver operating characteristic curve (AROC) was used to evaluate the ability of the models to discriminate between patients who lived and those who died (discrimination). ${ }^{21}$ The Hosmer-Lemeshow goodnessof-fit test was used to evaluate the model calibration. ${ }^{20} \mathrm{~A}$ two-tailed $P<0.05$ was considered statistically significant.

\section{RESULTS}

\section{Characterization of the Study Population}

A total of 429 patients were admitted to the ICUs and required RRT during the study period. Of these patients, 71 $(17 \%)$ received chronic dialysis for end-stage renal disease, $68(16 \%)$ received RRT in the ICU for $\leq 48 \mathrm{~h}$ and 30 (7\%) had missing data for the calculation of SOFA scores; as a result, all 169 were excluded from the study. Among patients who received RRT and stayed in the ICU for $\leq 48$ h, six (9\%) survived and were discharged to the wards. No patient received RRT for non-renal indication. Therefore, 
the remaining $260(61 \%)$ patients constituted the study population. The main characteristics of patients are depicted in Table 1. The most frequent reasons for ICU admission were sepsis $(\mathrm{n}=162,62 \%)$, postoperative complications $(\mathrm{n}=28,11 \%)$, cardiovascular complications $(\mathrm{n}=25$, $10 \%)$, AKI $(n=10,4 \%)$, trauma $(n=8,3 \%)$, neurological complications $(\mathrm{n}=8,3 \%)$ and miscellaneous $(\mathrm{n}=19,7 \%)$. Patients were admitted to the ICU at a median of $0(0-2)$ days after hospital admission.

The main contributing factors for AKI were sepsis
(77\%), ischemia/shock (67\%), contrast/nephrotoxins (29\%), major surgeries $(22 \%)$, rhabdomyolysis $(5 \%)$, urinary tract obstruction (4\%) and other reasons (5\%) (a patient could have more than one reason for AKI). CRRT was the initial modality of RRT in $222(85 \%)$ patients. The median time to the start of RRT was three (0-8) days after ICU admission. Ninety-one (35\%) patients received RRT the first day in the ICU, and $159(65 \%)$ did thereafter.

The median SOFA score (except renal points) on D1 was six (4-8) points and on D3 was seven (4-9) points.

Table 1 - Main demographic and clinical characteristics of patients ${ }^{a}$

\begin{tabular}{|c|c|c|c|c|c|}
\hline Variables & $\begin{array}{l}\text { All patients } \\
(\mathrm{n}=260)\end{array}$ & $\begin{array}{l}\text { A-SOFA <0 } \\
{[n=79(30)]}\end{array}$ & $\begin{array}{l}\text { A-SOFA =0 } \\
{[n=44(17)]}\end{array}$ & $\begin{array}{l}\text { A-SOFA >0 } \\
{[n=137(53)]}\end{array}$ & p-value ${ }^{b}$ \\
\hline Age (years) & $72.9 \pm 14.8$ & $70.7 \pm 17.1$ & $74.8 \pm 15.2$ & $73.5 \pm 13.2$ & 0.265 \\
\hline Male sex & $135(52)$ & $34(43)$ & $29(66)$ & $72(53)$ & $0.051^{\mathrm{c}}$ \\
\hline Hospital days prior to ICU admission (n) & $0(0-2)$ & $0(0-2)$ & $0(0-9)$ & $0(0-2)$ & 0.713 \\
\hline Medical admission & $209(80)$ & $68(86)$ & $39(89)$ & $102(75)$ & 0.037 \\
\hline Poor chronic health status (Knaus C or D) & $114(44)$ & $32(41)$ & $22(50)$ & $60(44)$ & 0.596 \\
\hline Charlson Comorbidity Index (points) & $3(1-4)$ & $2(1-4)$ & $3(2-5)$ & $3(1-4)$ & 0.149 \\
\hline Charlson Comorbidity Index $\geq 1$ point & $222(85)$ & $63(80)$ & $41(93)$ & $118(86)$ & 0.121 \\
\hline Body mass index $\left(\mathrm{Kg} / \mathrm{m}^{2}\right)$ & $26.0 \pm 5.0$ & $26.0 \pm 4.6$ & $25.5 \pm 3.8$ & $26.2 \pm 5.6$ & 0.741 \\
\hline SAPS II (ICU admission, points) & $47.5 \pm 10.6$ & $46.5 \pm 11.4$ & $48.6 \pm 9.7$ & $47.7 \pm 10.4$ & 0.551 \\
\hline SOFA on day 1 of RRT (except renal points) & $5.7 \pm 3.1$ & $6.3 \pm 3.0$ & $5.5 \pm 3.6$ & $5.3 \pm 2.9$ & $0.073^{\mathrm{d}}$ \\
\hline SOFA on day 3 of RRT (except renal points) & $6.4 \pm 3.5$ & $4.1 \pm 3.0$ & $5.5 \pm 3.6$ & $8.0 \pm 2.9$ & $<0.001^{\text {c,ddd,eee }}$ \\
\hline A-SOFA (SOFA D3 - SOFA D1) (points) & $1(-1-2)$ & $-2(-3--1)$ & $0(0-0)$ & $2(1-4)$ & $<0.001$ ccc,ddd,eee \\
\hline$\Delta$-SOFA (SOFA D3 - SOFA D1 / SOFA D1) & $0.1(-1.4-0.3)$ & $-0.3(0.5--0.2)$ & $0(0-0)$ & $0.3(0.2-0.8)$ & $<0.001$ ccc,ddd,eee \\
\hline \multicolumn{6}{|l|}{ RIFLE categories } \\
\hline Risk & $68(26)$ & $23(29)$ & $8(18)$ & $37(27)$ & \multirow[t]{3}{*}{0.676} \\
\hline Injury & $65(25)$ & $18(23)$ & $11(25)$ & $36(26)$ & \\
\hline Failure & $127(49)$ & $38(48)$ & $25(57)$ & $64(47)$ & \\
\hline Chronic kidney injury & $88(34)$ & $29(37)$ & $20(46)$ & $39(29)$ & $0.095^{\mathrm{e}}$ \\
\hline RRT at the first day of ICU & $91(35)$ & $30(38)$ & $15(34)$ & $46(34)$ & 0.800 \\
\hline Oliguria & $72(29)$ & $29(30)$ & $11(25)$ & $40(29)$ & 0.812 \\
\hline Sepsis & $200(77)$ & $66(84)$ & $33(75)$ & $101(74)$ & 0.243 \\
\hline Mechanical ventilation & $210(81)$ & $62(79)$ & $31(71)$ & $117(85)$ & $0.075^{\mathrm{e}}$ \\
\hline Vasopressors & $186(71)$ & $53(67)$ & $28(64)$ & $105(77)$ & 0.144 \\
\hline Length of ICU stay (days) & $19(10-37)$ & $19(13-37)$ & $23(11-38)$ & $19(9-35)$ & 0.477 \\
\hline Length of hospital stay (days) & $26(14-50)$ & $31(16-52)$ & $30(16-66)$ & $22(11-45)$ & $0.122^{\mathrm{d}}$ \\
\hline Decision to withhold/withdraw treatment & $43(17)$ & $10(13)$ & $8(20)$ & $25(19)$ & 0.524 \\
\hline ICU mortality & $185(71)$ & $44(56)$ & $34(77)$ & $107(75)$ & $0.001^{\mathrm{c}, \mathrm{ddd}}$ \\
\hline Hospital mortality & $194(75)$ & $48(61)$ & $37(84)$ & $109(80)$ & $0.003^{\mathrm{c}, \mathrm{dd}}$ \\
\hline
\end{tabular}

${ }^{\mathrm{a}}$ Results expressed as mean $\pm \mathrm{SD}$, median (IQR), $\mathrm{n}(\%)$.

${ }^{\mathrm{b}}$ Comparison among different categories of changes in associated organ failures based on A-SOFA.

${ }^{c} \mathrm{p}<0.05,{ }^{\mathrm{cc}} \mathrm{p}<0.01,{ }^{\mathrm{ccc}} \mathrm{p}<0.001$ for comparisons between patients in whom organ failures improved (A-SOFA $\left.<0\right)$ or remained unchanged $(\mathrm{A}-\mathrm{SOFA}=0)$. ${ }^{d} \mathrm{p}<0.05,{ }^{d d} \mathrm{p}<0.01,{ }^{\text {ddd }} \mathrm{p}<0.001$ for comparisons between patients in whom organ failures improved (A-SOFA $\left.<0\right)$ or worsened $(\mathrm{A}-\mathrm{SOFA}>0)$.

${ }^{e} \mathrm{p}<0.05,{ }^{\text {ee }} \mathrm{p}<0.01$, eee $\mathrm{p}<0.001$ for comparisons between patients in whom organ failures remained unchanged (A-SOFA $=0$ ) or worsened $(\mathrm{A}-\mathrm{SOFA}>0$ ). $\mathrm{SD}$ = standard deviation, IQR = interquartile range; ICU=intensive care unit; SAPS=Simplified Acute Physiology Score; SOFA=Sequential Organ Failure Assessment; RRT = renal replacement therapy 
The following organ dysfunctions $(\geq 1$ point in each domain) were observed on D1: respiratory $(n=207,80 \%)$, cardiovascular $(\mathrm{n}=189,73 \%)$, hematological $(\mathrm{n}=120,46 \%)$, hepatic $(n=45,17 \%)$ and neurological $(n=19,7 \%)$. The median A-SOFA was one $(-1-2)$ point, and the median $\Delta$-SOFA was $0.1(-1.4-0.3)$. According to the A-SOFA, organ dysfunctions improved in 79 (30\%), remained unchanged in 44 (17\%) and worsened in 137 (53\%) patients. Comparisons among the categories of A-SOFA scores are depicted in Table 1. Baseline (D1) organ dysfunctions were more severe in "improved" patients. "Worsened" patients had a lower frequency of medical admission. In general, there were not important differences in patients' characteristics among the groups (Table 1).

\section{Outcome analysis}

The overall ICU and hospital mortality rates were $71 \%$ and $75 \%$, respectively. The main outcome data for patients are presented in Table 1. Non-survivors were older than survivors $(75.4 \pm 12.9$ vs. $65.5 \pm 17.6$ years, $P<0.001)$ and had higher Charlson comorbidity scores [3 $(2-4)$ vs. $2(0-4)$, $P=0.023]$. As is predictable, SAPS II (49.2 \pm 9.7 vs. $42.5 \pm 11.5$, $P<0.001)$, SOFA D1 [6 $(4-8)$ vs. $5(2-7), P=0.011]$ and SOFA D3 [7 $(5-9)$ vs. $5(1-7), P<0.001]$ scores were higher in decedents than in survivors. A-SOFA [1 $(0-2)$ vs. $0(-2-0), P=0.019]$ and $\Delta$-SOFA [0.11 $(0.02-0.38)$ vs. 0 $(-0.33-0.25), P=0.016]$ were also higher in non-survivors (Figures 1a and 1b). However, neither the SAPS II score

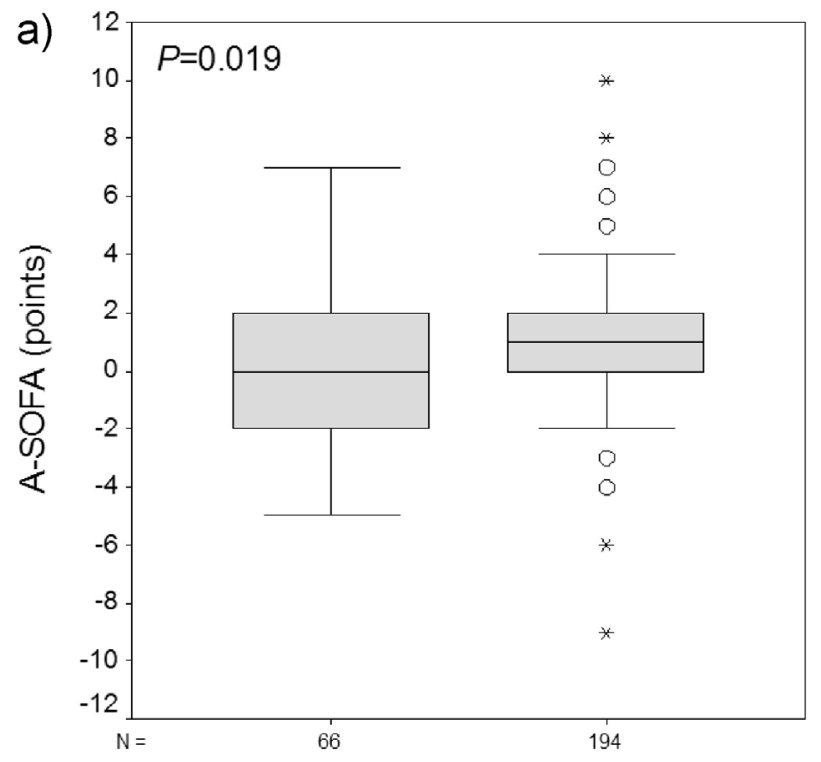

Survivors Non-survivors
[AROC $=0.69(95 \% \mathrm{CI}=0.61-0.76)]$, the A-SOFA $[$ AROC $=0.60(95 \% \mathrm{CI}=0.52-0.68)]$ nor the $\Delta$-SOFA [AROC $=$ $0.60(95 \% \mathrm{CI}=0.52-0.68)]$ discriminate survivors from non-survivors on an individual basis. In Figure 2, the mortality rates for the different possibilities of the A-SOFA according to

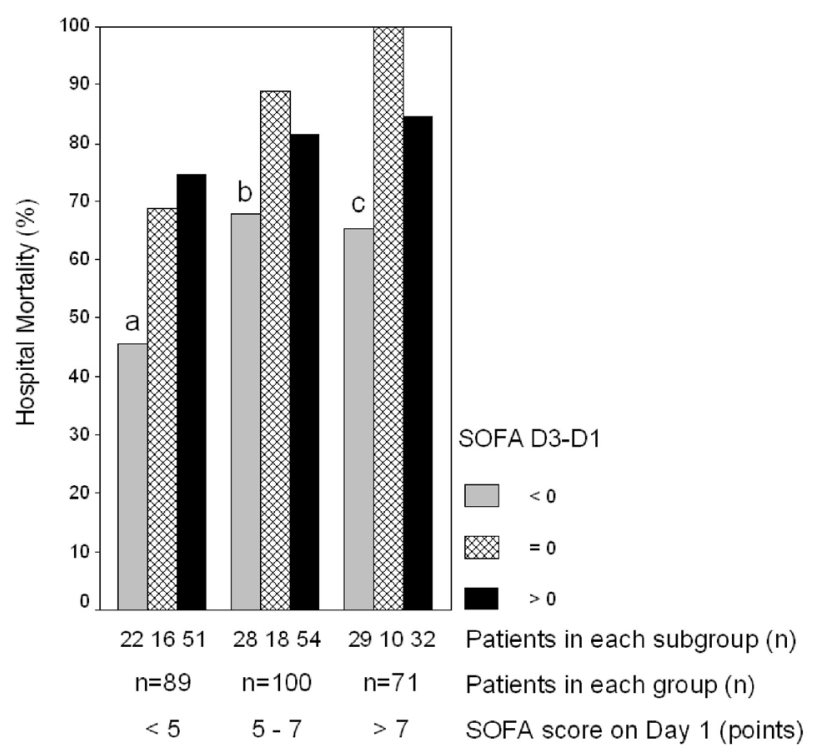

Figure 2 - Hospital mortality rates (y-axis) according to the degree of severity of organ failures on Day 1 . The values corresponding to the terciles of distribution of the SOFA score on Day 1 (SOFA D1) (x-axis) were used to establish a cut-off point for stratifying the patients into three groups (columns). Patients in whom associated organ failures improved (A-SOFA $<0$ ), remained unchanged (A-SOFA $=0$ ) and worsened (A-SOFA $>0$ ) are represented in gray, square-lined and black columns, respectively. a) $P=$ 0.05 ; b) $P=0.19$; c) $P=0.04$.

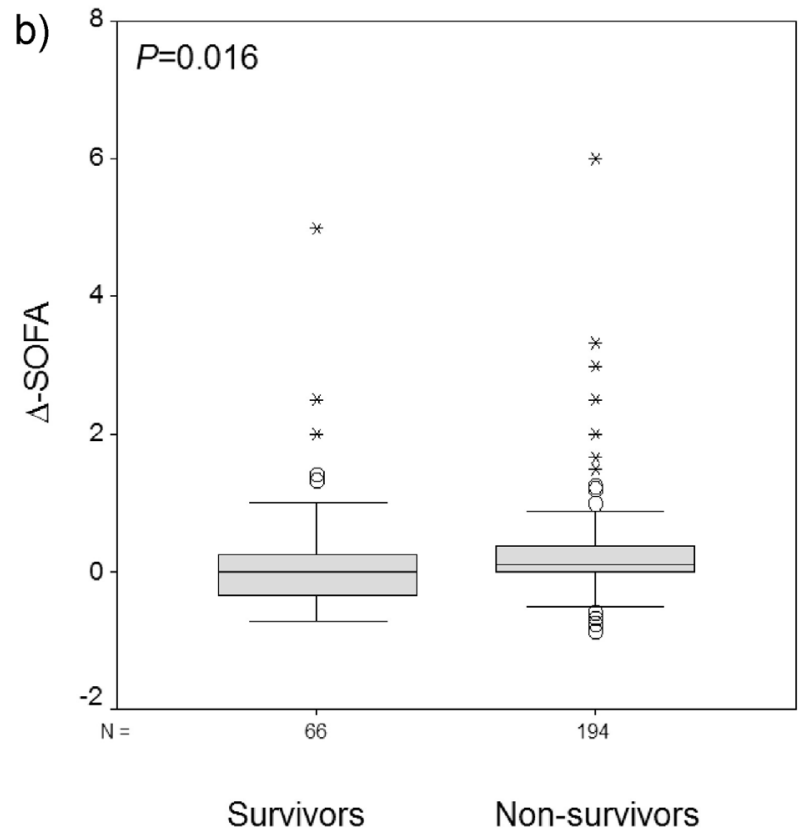

Figure 1 - Boxplot graphics representing the comparisons of absolute (A-SOFA) [Figure 1a] and relative ( $\Delta$-SOFA) [Figure 1b] changes in associated organ failures between survivors and non-survivors. $P$-values refer to the Mann-Whitney U test. 
the different degrees of severity of organ failures at baseline (SOFA-D1) are depicted. The values corresponding to the terciles of distribution of the SOFA score on D1 (SOFA D1) were used to establish a cut-off point to stratify the patients into three groups. The hospital mortality was significantly higher in patients in whom organ dysfunction worsened or remained unchanged.

The results of univariate analysis of predictive factors for increased hospital mortality are depicted in Table 2. Older age, poor chronic health status, presence of comorbidities, body mass index, SOFA D1, A-SOFA, $\Delta$-SOFA and A-SOFA categories were associated with a worse outcome. Three multivariate analyses were performed, entering either A-SOFA, $\triangle$-SOFA or A-SOFA categories in separate models (Table 3). The main independent outcome predictors were older age, the presence of comorbidities, poor functional capacity, baseline organ dysfunctions (SOFA D1) and all forms of evaluation of changes in organ dysfunctions. Patients in whom organ dysfunction worsened or remained unchanged had a worse outcome adjusting for other

Table 2 - Univariate analysis of factors associated with increased hospital mortality $(n=260)$

\begin{tabular}{|c|c|c|c|}
\hline Variables & $\begin{array}{c}\text { Mortality } \\
(\%)\end{array}$ & $\begin{array}{c}\text { Odds-ratios } \\
(95 \% \mathrm{CI})\end{array}$ & p-value \\
\hline Age (years) & - & $1.04(1.02-1.06)$ & $<0.001$ \\
\hline \multicolumn{4}{|l|}{ Gender } \\
\hline Female & 71 & 1.00 & \multirow[t]{2}{*}{0.282} \\
\hline Male & 78 & $1.42(0.81-2.48)$ & \\
\hline \multicolumn{4}{|c|}{ Poor chronic health status (Knaus C or D) } \\
\hline No & 62 & 1.00 & \multirow[t]{2}{*}{$<0.001$} \\
\hline Yes & 90 & $5.66(2.79-11.47)$ & \\
\hline \multicolumn{4}{|l|}{ Charlson comorbidity index (points) } \\
\hline 0 & 50 & 1.00 & \multirow[t]{2}{*}{$<0.001$} \\
\hline$\geq 1$ & 79 & $3.72(1.83-7.59)$ & \\
\hline \multicolumn{4}{|l|}{ Type of admission } \\
\hline Surgical & 67 & 1.00 & \multirow[t]{2}{*}{0.202} \\
\hline Medical & 77 & $1.63(0.84-3.17)$ & \\
\hline Days prior to ICU admission (Ln) & - & $1.058(0.90-1.30)$ & 0.426 \\
\hline \multicolumn{4}{|l|}{ Mechanical ventilation } \\
\hline No & 74 & 1.00 & \multirow[t]{2}{*}{0.999} \\
\hline Yes & 75 & $1.04(0.52-2.11)$ & \\
\hline \multicolumn{4}{|l|}{ Sepsis } \\
\hline No & 70 & 1.00 & \multirow[t]{2}{*}{0.443} \\
\hline Yes & 76 & $1.36(0.72-2.58)$ & \\
\hline \multicolumn{4}{|l|}{ Vasopressors } \\
\hline No & 68 & 1.00 & \multirow[t]{2}{*}{0.135} \\
\hline Yes & 76 & $1.62(0.91-2.90)$ & \\
\hline \multicolumn{4}{|l|}{ Acute on chronic kidney injury } \\
\hline No & 74 & 1.00 & \multirow[t]{2}{*}{0.801} \\
\hline Yes & 76 & $1.13(0.62-2.05)$ & \\
\hline \multicolumn{4}{|l|}{ RRT on the first day in ICU } \\
\hline No & 78 & 1.00 & \multirow[t]{2}{*}{0.107} \\
\hline Yes & 68 & $0.60(0.34-1.06)$ & \\
\hline \multicolumn{4}{|l|}{ Oliguria } \\
\hline No & 73 & 1.00 & \multirow[t]{2}{*}{0.425} \\
\hline Yes & 79 & $1.37(0.72-2.59)$ & \\
\hline SOFA D1 & - & $1.13(1.03-1.25)$ & 0.009 \\
\hline A-SOFA & - & $1.13(1.01-1.26)$ & 0.038 \\
\hline$\Delta$-SOFA & - & $1.26(0.86-1.84)$ & 0.231 \\
\hline \multicolumn{4}{|l|}{ A-SOFA categories } \\
\hline Improved $(<0)$ & 61 & 1.00 & \multirow[t]{3}{*}{0.003} \\
\hline Remained unchanged $(=0)$ & 84 & $3.41(1.35-8.61)$ & \\
\hline Worsened (>0) & 80 & $2.51(1.36-4.64)$ & \\
\hline
\end{tabular}

$\mathrm{CI}=$ confidence interval; $\mathrm{ICU}=$ intensive care unit; SOFA = Sequential Organ Failure Assessment. 
significant covariates. All multivariate models had both good calibration and discrimination (Table 3). Sepsis, acute on chronic kidney dysfunction and oliguria were forced into the final models and were not selected. The SAPS II score

Table 3 - Multivariate analyses of factors associated with increased hospital mortality $(\mathrm{n}=260)$

\begin{tabular}{|c|c|c|}
\hline Variables & $\begin{array}{l}\text { Odds-ratios } \\
(95 \% \text { CI })\end{array}$ & $P$ value \\
\hline \multicolumn{3}{|l|}{ Model including A-SOFA ${ }^{\text {a }}$} \\
\hline Age (years) & $1.03(1.01-1.06)$ & 0.021 \\
\hline \multicolumn{3}{|c|}{ Charlson comorbidity index (points) } \\
\hline 0 & 1.00 & \\
\hline$\geq 1$ & $3.84(1.57-9.39)$ & 0.003 \\
\hline \multicolumn{3}{|c|}{ Poor chronic health status (Knaus C or D) } \\
\hline No & 1.00 & \\
\hline Yes & $3.37(1.49-7.65)$ & 0.004 \\
\hline \multicolumn{3}{|l|}{ Type of admission } \\
\hline Surgical & 1.00 & 0.049 \\
\hline Medical & $2.27(1.00-5.13)$ & \\
\hline SOFA D1 & $1.32(1.16-1.49)$ & $<0.001$ \\
\hline A-SOFA & $1.27(1.10-1.46)$ & 0.001 \\
\hline \multicolumn{3}{|l|}{ Model including $\Delta$-SOFA ${ }^{\text {b }}$} \\
\hline Age (years) & $1.03(1.00-1.06)$ & 0.024 \\
\hline \multicolumn{3}{|c|}{ Charlson comorbidity index (points) } \\
\hline 0 & 1.00 & \\
\hline$\geq 1$ & $3.38(1.41-8.08)$ & 0.006 \\
\hline \multicolumn{3}{|c|}{ Poor chronic health status (Knaus C or D) } \\
\hline No & 1.00 & \\
\hline Yes & $3.90(1.74-8.75)$ & 0.001 \\
\hline SOFA D1 & $1.31(1.16-1.48)$ & $<0.001$ \\
\hline$\Delta$-SOFA & $1.84(1.16-2.91)$ & 0.009 \\
\hline \multicolumn{3}{|c|}{ Model including A-SOFA categories ${ }^{c}$} \\
\hline Age (years) & $1.03(1.00-1.06)$ & 0.022 \\
\hline \multicolumn{3}{|c|}{ Charlson comorbidity index (points) } \\
\hline 0 & 1.00 & \\
\hline$\geq 1$ & $3.34(1.37-8.14)$ & 0.008 \\
\hline \multicolumn{3}{|c|}{ Poor chronic health status (Knaus C or D) } \\
\hline No & 1.00 & \\
\hline Yes & $3.60(1.58-8.22)$ & 0.002 \\
\hline \multicolumn{3}{|l|}{ Type of admission } \\
\hline Surgical & 1.00 & 0.066 \\
\hline Medical & $2.15(0.96-4.87)$ & \\
\hline SOFA D1 & $1.29(1.14-1.45)$ & $<0.001$ \\
\hline \multicolumn{3}{|l|}{ A-SOFA categories } \\
\hline Improved $(<0)$ & 1.00 & \\
\hline Remained unchanged $(=0)$ & $4.29(1.45-12.72)$ & 0.009 \\
\hline Worsened $(>0)$ & $4.07(1.91-4.87)$ & $<0.001$ \\
\hline
\end{tabular}

$\mathrm{CI}=$ confidence interval; SOFA $=$ Sequential Organ Failure Assessment. ${ }^{\mathrm{a}} \mathrm{AROC}=0.81(95 \% \mathrm{CI}=0.75-0.87)$; Hosmer-Lemeshow goodness-of-fit $\left(\chi^{2}=4.144 ; P=0.844\right)$.

${ }^{\mathrm{b}}$ AROC $=0.72(95 \% \mathrm{CI}=0.65-0.80) ;$ Hosmer-Lemeshow goodness-of-fit $\left(\chi^{2}=8.234 ; P=0.411\right)$.

${ }^{\mathrm{c}}$ AROC $=0.73(95 \% \mathrm{CI}=0.66-0.80) ;$ Hosmer-Lemeshow goodness-of-fit $\left(\chi^{2}=6.241 ; P=0.620\right)$. was also entered into the final models ( $\mathrm{OR}=1.02$ (0.98-1.06), $\mathrm{p}=0.267$ in the model which included the A-SOFA; OR $=1.02$ (0.98-1.06), $\mathrm{p}=0.241$ in the model which included the $\Delta$-SOFA; OR $=1.02$ (0.98-1.06), $\mathrm{p}=0.258$ in the model which included the A-SOFA categories). The SAPS II score was not selected in all of them, and in general, the effects of the other covariates remained unchanged.

\section{DISCUSSION}

Although changes in organ dysfunctions have already been reported to be associated with outcomes in general ICU patients ${ }^{22}$, information on this subject in patients with AKI is limited. Patients with AKI have higher mortality rates, especially when RRT is required, and their outcomes are significantly worse than those of other patients. ${ }^{1-5}$ It has long been known that prognostic scores or even specific renal scores used at ICU admission do not perform well in the AKI population. ${ }^{23,24}$ In the present multicenter study, we have prospectively investigated the effect of early changes in associated organ dysfunctions on the mortality of a large cohort of critically ill patients with AKI in need of RRT. We employed the SOFA score, a simple, validated and widely used organ dysfunction score for this purpose. Our results demonstrated that, in addition to well-known outcome predictors, such as older age, medical admission, a poor previous chronic health status, comorbidities and the severity of baseline organ dysfunctions, the sequential trend in associated organ dysfunctions over the first three days of RRT was associated with increased hospital mortality. However, it was also demonstrated that these trends in organ dysfunctions as a single parameter were not able to discriminate survivors and non-survivors and that they therefore should not be used to predict outcome on an individual basis.

Previous studies have reported that the outcomes of patients with AKI are worse in the context of multiple organ dysfunctions and that mortality rates increase with the number of organ dysfunctions. ${ }^{1,4}$ Organ dysfunctions are an ongoing event changing over the clinical course of ICU patients, and their evaluation at a static point may not always reflect the real patient's clinical condition. Changes in SOFA scores over the first $24 \mathrm{~h}$ or $48 \mathrm{~h}$ have been demonstrated to refine outcome prediction in patients with severe sepsis ${ }^{8}$ and in general ICU patients, ${ }^{7}$ respectively. Chertow et al..$^{25}$ reported an enhanced prediction power with the sequential analysis of different prognostic scores, including SOFA score, in the AKI population.

Although it is intuitive that the course of associated organ dysfunctions correlates with outcomes in patients with AKI in need of RRT, to the best of our knowledge only two 
previous studies have addressed this issue..$^{10,11}$

Kikuchi et al. ${ }^{11}$ evaluated 40 patients who underwent different extracorporeal blood purification procedures. However, in addition to patients with AKI receiving RRT ( $45 \%$ of the entire population), they also evaluated patients treated with plasma exchange, bilirubin and endotoxin adsorption. In accord with our results, they demonstrated that although changes in SOFA scores did not discriminate mortality on an individual basis, non-survivors had higher maximum SOFA scores and higher changes in SOFA scores during RRT procedures than survivors.

More recently, Cappi et al. ${ }^{10}$ retrospectively evaluated 111 patients with AKI in need of RRT. In that study, independent predictors of increased ICU mortality were cardiovascular dysfunction at ICU admission, changes in total SOFA scores over the first $24 \mathrm{~h}$ of ICU stay and older age. However, as acknowledged by the authors, the study was limited by its retrospective design and by a relatively small sample size. In addition, many other outcome predictors such as comorbidities and chronic health status, which would be interesting to adjust for, were not evaluated.

In a very elegant study, Levy et al. ${ }^{8}$ evaluated the impact of changes in total SOFA score and its domains over the first $24 \mathrm{~h}$ in 1,034 patients with severe sepsis. They demonstrated that improvements in organ dysfunctions correlated significantly with survival. By contrast, patients in whom organ dysfunctions remained unchanged or worsened presented with comparatively higher 28-day mortality rates. These observations are in agreement with our results. In our study, the multivariate analysis showed four-fold higher odds of hospital mortality in patients with AKI in whom the associated organ failures remained unchanged or worsened in comparison to those in whom organ failures improved. These facts remained significant even when the patients were stratified according to the severity of baseline organ dysfunctions.

Nonetheless, there are some limitations in our study which must be taken into account in the generalization of its results. First, although patients from three tertiary-care centers were included, the study was restricted to a specific geographic area. Moreover, the decision to start RRT was left at the discretion of the attending nephrologist and intensivist. Even though it is reasonable to presume that the criteria employed in this study are similar to those accepted in many ICUs, indications for RRT vary significantly among institutions. Due to the non-interventional nature of the present study, it is not possible to conclude whether changes in organ failures over time can be used to evaluate the response to RRT. In a recent report, $\mathrm{Sakr}$ et al. ${ }^{26}$ have demonstrated the applicability of daily renal SOFA score analysis as an evaluation tool for starch effects in renal function. However, it should be emphasized that no prognostic score, including severity of organ failure scores, can be used as the only parameter in decisions related to the patient's care. Another criticism to consider is that SOFA scores should ideally have been collected daily while RRT was used. However, the decision to measure changes in SOFA scores on D1 and D3 was made based on the study of Ferreira et al. ${ }^{7}$ In that study, changes in SOFA score over the first $48 \mathrm{~h}$ better predicted mortality than changes observed on the subsequent days did. Finally, the mortality rates of our patients were high. However, our patient population is significantly old $(69 \%$ of the patients were older than 70 years), $85 \%$ had comorbidities and $44 \%$ had poor chronic health status. Older age, severity of comorbidities and poor chronic health status are well-known risk factors for increased mortality in critically ill patients.

Our results indicate that early changes in SOFA score after the start of RRT were associated with hospital mortality of patients with AKI. Adjusting for other relevant covariates, including the initial severity of organ dysfunctions, patients in whom SOFA scores worsened or remained unchanged had poorer outcomes. On the other hand, a decrease in SOFA score over the first three days of RRT was associated with improved survival in patients with AKI. In conjunction with clinical judgment, and taking into consideration the patient's preferences and values, the knowledge of these outcome predictors may be useful in helping physicians make decisions in the care of these patients and in improving discussions of a patient's prognosis. However, changes in SOFA scores did not discriminate outcomes on an individual basis and should not be used as a single parameter for predicting outcomes and evaluating patients' response to therapeutic interventions such as RRT.

\section{REFERENCES}

1. Uchino S, Kellum JA, Bellomo R, Doig GS, Morimatsu H, Morgera $\mathrm{S}$, et al. Acute renal failure in critically ill patients: a multinational, multicenter study. JAMA. 2005;294:813-8.
2. Metnitz PG, Krenn CG, Steltzer H, Lang T, Ploder J, Lenz K, et al. Effect of acute renal failure requiring renal replacement therapy on outcome in critically ill patients. Crit Care Med. 2002;30:2051-8. 
3. de Mendonca A, Vincent JL, Suter PM, Moreno R, Dearden NM, Antonelli $\mathrm{M}$, et al. Acute renal failure in the ICU: risk factors and outcome evaluated by the SOFA score. Intensive Care Med. 2000;26:915-21.

4. Maccariello E, Soares M, Valente C, Nogueira L, Valenca RV, Machado JE, et al. RIFLE classification in patients with acute kidney injury in need of renal replacement therapy. Intensive Care Med. 2007;33:597-605.

5. Silvester W, Bellomo R, Cole L. Epidemiology, management, and outcome of severe acute renal failure of critical illness in Australia. Crit Care Med. 2001;29:1910-5.

6. Mehta RL, Pascual MT, Gruta CG, Zhuang S, Chertow GM. Refining predictive models in critically ill patients with acute renal failure. J Am Soc Nephrol. 2002;13:1350-7.

7. Ferreira FL, Bota DP, Bross A, Melot C, Vincent JL. Serial evaluation of the SOFA score to predict outcome in critically ill patients. JAMA. 2001;286:1754-8.

8. Levy MM, Macias WL, Vincent JL, Russell JA, Silva E, Trzaskoma B, et al. Early changes in organ function predict eventual survival in severe sepsis. Crit Care Med. 2005;33:2194-201.

9. Cabre L, Mancebo J, Solsona JF, Saura P, Gich I, Blanch L, et al. Multicenter study of the multiple organ dysfunction syndrome in intensive care units: the usefulness of Sequential Organ Failure Assessment scores in decision making. Intensive Care Med. 2005;31:927-933.

10. Cappi SB, Sakr Y, Vincent JL. Daily evaluation of organ function during renal replacement therapy in intensive care unit patients with acute renal failure. J Crit Care. 2006;21:179-83.

11. Kikuchi H, Maruyama H, Omori S, Kazama JJ, Gejyo F. The sequential organ failure assessment score as a useful predictor for estimating the prognosis of systemic inflammatory response syndrome patients being treated with extracorporeal blood purification. Ther Apher Dial. 2003; 7:456-60.

12. Bellomo R, Ronco C, Kellum JA, Mehta RL, Palevsky P. Acute renal failure - definition, outcome measures, animal models, fluid therapy and information technology needs: the Second International Consensus Conference of the Acute Dialysis Quality Initiative (ADQI) Group. Crit Care. 2004;8:R204-12.

13. Vincent JL, Moreno R, Takala J, Willatts S, De Mendonca A, Bruining H. The SOFA (Sepsis-related Organ Failure Assessment) score to describe organ dysfunction/failure. On behalf of the Working Group on SepsisRelated Problems of the European Society of Intensive Care Medicine. Intensive Care Med. 1996;22:707-10.

14. Bastos PG, Sun X, Wagner DP, Wu AW, Knaus WA. Glasgow coma scale in the evaluation of outcome in the intensive care unit: findings from the Acute Physiology and Chronic Health Evaluation III study. Crit Care Med. 1993;21:1459-65.
15. Le Gall J-R, Lemeshow S, Saulnier F. A new simplified acute physiology score (SAPS II) based on a European/North American multicenter study. JAMA. 1993;270:2957-63.

16. Knaus WA, Zimmerman JE, Wagner DP, Draper EA, Lawrence DE. APACHE - acute physiology and chronic health evaluation: a physiologically based classification system. Crit Care Med. 1981;9:591-7.

17. Charlson ME, Pompei P, Ales KL, MacKenzie CR. A new method of classifying prognostic comorbidity in longitudinal studies: development and validation. J Chronic Dis. 1987;40:373-83.

18. Bone RC, Balk RA, Cerra FB, Dellinger RP, Fein AM, Knaus WA, et al. Definitions for sepsis and organ failure and guidelines for the use of innovative therapies in sepsis. The ACCP/SCCM Consensus Conference Committee. American College of Chest Physicians/Society of Critical Care Medicine. Chest. 1992;101:1644-55.

19. Garner JS, Jarvis WR, Emori TG, Horan TC, Hughes JM. CDC definitions for nosocomial infections, 1988. Am J Infect Control. $1998 ; 16: 128-40$

20. Hosmer DW, Lemeshow S: Applied logistic regression. New York: Wiley-Interscience; 2000.

21. Hanley JA, McNeil BJ. The meaning and use of the area under receiver operating characteristic (ROC) curve. Radiology. 1982;143:29-36.

22. Park M, Azevedo LCP, Maciel AT, Pizzo VR, Noritomi DT, Cruz Neto LM da. Evolutive standard base excess and serum lactate level in severe sepsis and septic shock patients resuscitated with early goal-directed therapy: still outcome markers?. Clinics. 2006;61:47-52.

23. Uchino S, Bellomo R, Morimatsu H, Morgera S, Schetz M, Tan I, et al. External validation of severity scoring systems for acute renal failure using a multinational database. Crit Care Med. 2005;33:1961-7.

24. Lima EQ, Zanetta DM, Castro I, Massarollo PC, Mies S, Machado $\mathrm{MM}$, et al. Mortality risk factors and validation of severity scoring systems in critically ill patients with acute renal failure. Ren Fail. 2005;27:547-56

25. Chertow GM, Soroko SH, Paganini EP, Cho KC, Himmelfarb J, Ikizler $\mathrm{TA}$, et al. Mortality after acute renal failure: models for prognostic stratification and risk adjustment. Kidney Int. 2006;70:1120-6.

26. Sakr Y, Payen D, Reinhart K, Sipmann FS, Zavala E, Bewley J, et al. Effects of hydroxyethyl starch administration on renal function in critically ill patients. Br J Anaesth. 2007;98:216-24. 